\title{
Interview with Abel Laureate Yves Meyer
}

Bjørn lan Dundas (University of Bergen. Norway) and Christian Skau (Norwegian University of Science and Technology, Trondheim, Norway)

Professor Yves Meyer, congratulations on being awarded the Abel Prize 2017 for your pivotal role in the development of the mathematical theory of wavelets. You will receive the Abel Prize from His Majesty the King of Norway in a ceremony tomorrow. The history of wavelets is fascinating and some aspects of it are old, but before we delve deeper into the mathematical side of things, perhaps you could share a bit of your personal journey.

\section{Becoming a mathematician}

You spent most of your childhood in Tunis. You attended the Lycée Carnot, which we understand was a very intellectually stimulating environment. But you were interested in many subjects. Why did you turn toward mathematics?

Yes, that was not an obvious choice because I was more interested in humanities. I was in love with Socrates and Plato, and I am still reading Plato right now, day after day, night after night. I am no longer reading Plato in Greek but I used to do that. I would say my main interest is literature. The point is that I am a bad writer. That is my bad side. So, I took mathematics because I was gifted - I was unusually gifted in mathematics. I cannot explain that. I understood mathematics from the inside in a very natural way. When I was in high school, I understood mathematics by myself and not by listening to my teachers.

\section{So, you did not have any role models you found inspir-} ing?

I had very good teachers and the teachers assessed me as being gifted in mathematics. The teachers were a stimulation but I had my own perception of mathematics. I had naive misconceptions. For example, I was thinking that all functions were continuous. And for me, you know, it was obvious and my mathematics was the mathematics of the time of Euler. So, not only were all functions continuous but they were all analytic.

Euler was also Abel's teacher! Abel learned mathematics from reading Euler.

That's beautiful - so we are back to Abel! It took me a while to understand that mathematics was not the toy I was playing with in my childhood. There were distinct subjects, so I had to mature to that fact when I was 19. That was rather difficult because, for me, mathematics was obvious. I always found a solution of a problem but with my own way of thinking, which was not canonical.

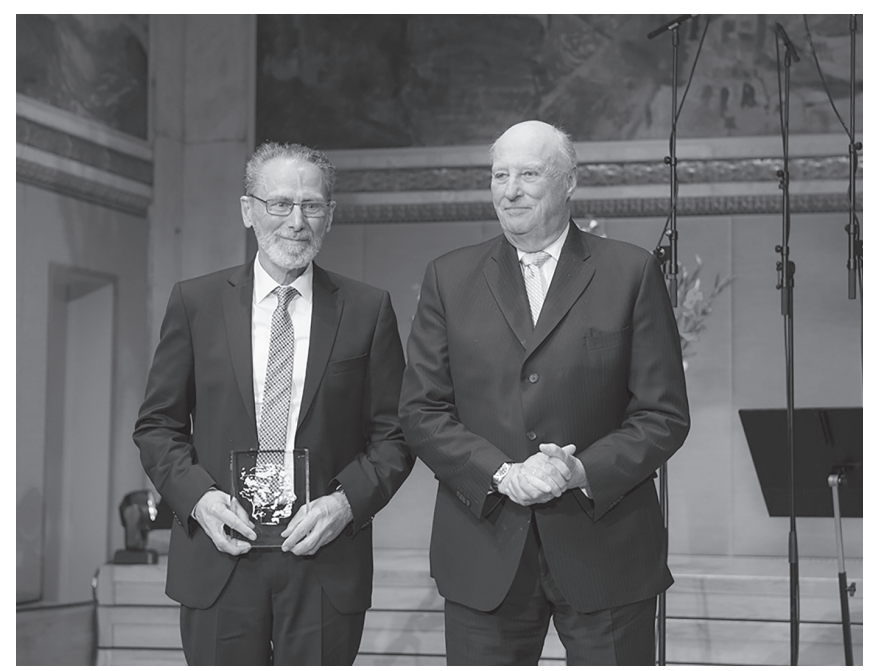

Yves Meyer received the Abel Prize from King Harald of Norway. (Photo: Thomas Brun)

So, in 1956, as a 17 year old, when you returned to France in order to prepare for the entering exam to the elite school l'École Normale Supérieure, you had mathematics as a career choice, would you say?

No, I was still hesitating. I took mathematics as a major because I was more gifted in mathematics than in humanities. Also, of course, I had to earn my living so I took mathematics for getting a job.

In 1957, after only one year of training at what in France is called "Classes de Préparation aux Grandes Écoles", you entered l'École Normale Supérieure in Paris, coming first in the entrance examination in mathematics. Could you give us a glimpse of your years there?

When I was at l'École Normale Supérieure, we were mixed with people in humanities. We were about 40 scientists - maths and physics - and 40 kids in humanities. And most of the time, I was discussing with my schoolmates in humanities, spending hours and hours. There was a Japanese student that was admitted as a foreign student, Abe Yoshio was his name - he is dead now. To my great surprise he wrote a memoir about the times at l'École Normale Supérieure. I read very recently the page of his memoir where I was described. According to Abe Yoshio, I am described as the only scientist to whom he could talk. So, for him, I was different, and I felt about myself that I was different. I was not obsessed by science. Now I have completely changed; now I am completely obsessed by science. But that took a part of my life to come around to. But in the beginning - because you always have a certain inertia in your life - since I 
had focused on humanities until my Baccalaureate (that is, the end of high school), the influence of humanities remained for about 10 years before I was convinced that mathematics was something absolutely marvellous. In the beginning, it was, in a sense, a little bit too easy for me to pass the exams, which was not doing mathematics at a research level. Then it could not be serious or such a big deal, I thought.

After three years as a teacher at Prytanée National Militaire (an experience we hope we can come back to when we talk about teaching in general), you moved to Strasbourg. Can you tell us something about those years and how you ended up doing your thesis in harmonic analysis?

The atmosphere at the Department of Mathematics at Strasbourg was absolutely marvellous. Because it was a very small department, there were 14 full professors. I was a teaching assistant and there were altogether 14 teaching assistants in the department. All the teaching assistants worked in just one office - a large office - and everyone was smoking. It was impossible to work, so we were just discussing. We were in complete freedom, so we could choose the subject of our PhD just by our own inclination, without a supervisor, so I decided upon my choice of thesis after reading the book by Antoni Zygmund: Trigonometric Series. I found the book fascinating and I asked myself what were the important problems in this subject? So I decided what were the important problems and I tried to solve the problems. I wrote 12 chapters of my thesis, my wife typed these 12 chapters and then I asked: "Who could be a supervisor of the thesis?" Pierre Cartier, who was a professor at the Université de Strasbourg, advised me to contact Jean-Pierre Kahane. So I took the train, brought to Jean-Pierre Kahane the 12 chapters and asked him to give me a PhD subject. And he said: "It is ridiculous - you have already written a PhD." And so I got a PhD that way. But if you do it that way it means that you are either stupid or arrogant. The penalty came immediately: at exactly the time I was submitting my thesis, Elias Stein proved a much better theorem. Elias Stein was still at the University of Chicago working with Alberto Calderón and they had made much more progress on the same problem I was doing.

\section{Stein had much stronger tools, didn't he?}

Yes, he had much stronger tools.

\section{Number theory and quasicrystals}

\section{Is that why you decided to move to Diophantine ap-} proximations?

Yes. I was hired at the Université d'Orsay and then I was influenced by Jean-Pierre Kahane. He had a very good influence on me. The idea was that, in general, after you get a PhD, you should change subject because you should not remain under the influence of your supervisor. In my case, I had no supervisor but I decided to change subject anyway. At that time, the book by Jean-Pierre Kahane and Raphaël Salem, Ensembles parfaits et séries trigono- métriques, appeared. I read the book and I fell in love with it. I decided to solve one of the main problems that Salem could not solve because he died prematurely. That took me about three or four years; it was a problem in number theory.

The keywords here are Pisot and Salem numbers. Actually, the concept of Pisot number was first introduced by the Norwegian mathematician Axel Thue, in connection with Diophantine approximations. A Pisot number is a real algebraic integer $\theta$ greater than 1 such that the conjugate numbers to $\theta$ have absolute values less than 1. A Salem number has the same definition except that the absolute values should be less than or equal to 1 with at least one having absolute value 1 . There is a very fascinating story about these numbers. You won the Salem prize the third time it was awarded in 1970 and that was because you proved a theorem that Salem had posed, which you already alluded to. Could you describe it?

It's a fascinating story. I discovered quasicrystals by accident because they were a tool for solving this problem. The concept of quasicrystals did not exist at that time but it turned out they were exactly the correct tool for solving the problem raised by Salem. In solving this problem, I proved the following theorem, which is my favourite result. I can explain that almost with my bare hands. So, you have something that is now called a Meyer set. I called these sets "quasicrystals" - a precursor of this concept was my definition of a "model set" from as far back as 1972 - but Robert Moody later called them "Meyer sets". So a Meyer set is a set of points in $\mathbb{R}^{n}$ - so if $n$ is 2 we are in the plane - that has two conflicting properties: the set is spread uniformly, which means that there is a radius $R$ so large that each ball of radius $R$, whatever the location, contains at least one point, so the points are spread uniformly; but there are no concentrations, which means there is a small radius $r$ such that each ball of radius $r$, whatever its location, contains at most one point.

\section{This is what is called a Delone set, right?}

Delone set, exactly! So, a Meyer set can be defined just by the following property - the definition is due to Jeffrey Lagarias, which improves a little bit on my definition - it is a Delone set $\Lambda$ such that the set $\Lambda-\Lambda$ of all differences is still a Delone set. That is a Meyer set. So that is something I introduced with a seemingly more restrictive definition but Lagarias proved that my definition is identical to this one. And then you ask yourself, is it possible that a Meyer set $\Lambda$ will be self-similar in the sense that for $\theta$ a real number, $\theta$ larger than $1, \theta \Lambda$ would be contained in $\Lambda$ ? For instance, if $\Lambda$ is an ordinary lattice and $\theta$ is a real number then $\theta \Lambda$ is contained in $\Lambda$ if and only if $\theta$ is an integer. Amazingly, for a general Meyer set $\Lambda$, this is true if and only if $\theta$ is either a Pisot or a Salem number.

\section{That is remarkable!}

That is the most beautiful theorem I have proved. I love this theorem! It combines, you know, geometry and number theory. There is no analysis in this theorem, which is 
truly remarkable! And the converse is true: that is, if you are given a Pisot or a Salem number $\theta$, there is always a Meyer set $\Lambda$ such that $\theta \Lambda$ is contained in $\Lambda$.

What is the connection with quasicrystals, more specifically?

People discovered that in a very, I would say, accidental way. Once they understood the construction rule of a quasicrystal, which is the construction that I have given in my book Algebraic Numbers and Harmonic Analysis from 1972, they observed that there is what they call "inflation" of a quasicrystal, that a quasicrystal is self-similar. But they did not know that at the time because my book was pulped by the publisher Elsevier.

You mean it was not accessible or was out of print?

No, no, not out of print. It was destroyed! Elsevier wrote me a letter asking me for permission to destroy the copies that were left because there were too many copies and it was impossible to sell that garbage anymore, so they thought, I imagine. Of course I accepted because I was doing something else. I was no longer interested in what I had written; it was already remote past, you know.

What a fascinating story! Your book contains material that can aptly be described as a precursor - which went unnoticed for a long time - of quasicrystals. In fact, it essentially contains the abstract theory of the cut-andproject method, in the full generality of locally compact abelian groups. To cut a long story short, Roger Penrose subsequently introduced his tilings in 1974, and later came Dan Shechtman, in 1982, who discovered that you find quasiperiodic crystals in nature (for which he received the Nobel Prize for Chemistry in 2011). Who made the connection with what you had done?

I think Enrico Bombieri made the connection and then Robert Moody, who was an important person in this. Bombieri suspected that there was a connection and it was understood completely by Moody. Moody is a very fair person, a remarkably open-minded person. He read my book in full detail. And he observed that everything was predicted in some sense. Like Nostradamus in some obscure language! One more thing should be mentioned concerning Meyer sets and tilings. If $\Lambda$ is a Meyer set in $\mathbb{R}^{n}$ and $V(\Lambda)$ is the associated Voroni cells these cells are simply connected polytopes - then $V(\Lambda)$ is a tiling of $\mathbb{R}^{n}$. What is remarkable is that there are only a finite number of Voronoi cells up to translation and so one gets a translation tiling of $\mathbb{R}^{n}$ by a finite number of prototiles.

\section{Calderón's conjecture}

We move to the next big chapter in your mathematical discoveries and that is the solution of Alberto Calderón's conjecture. There is a long story behind that but the crowning achievement was the paper you wrote jointly with Ronald Coifman and Alan McIntosh that was published in 1982. Could you tell the story of this cooperation?
Oh yes, the story is so beautiful. It is, in many ways, an accidental story. It is a story I like very much because it relates to my younger years in Tunis. Arabic people have a tendency to be fatalists. They will say everything is written in the Book. You cannot avoid your fate, your destiny. It was a time when my colleagues in Orsay for some political reasons refused to give graduate courses. They were objecting to a decision by the Minister of Education or something. I hate to follow the crowd and so I decided to give a graduate course anyway, just to prove that I do not follow the crowd. So I gave the graduate course and there was a student following the course who was completely distinct from the other students and who seemed to be much older. So I spoke to this person. He was from Australia and his name was Alan McIntosh. I invited him to have lunch at the end of the course every week. After three weeks, he explained what he was trying to find - his programme. His programme was exactly what I was trying to do with Coifman, but he was a student of another mathematician Tosio Kato. Kato (he is dead now) was working in operator theory but from a very abstract viewpoint. Kato had a general conjecture from which Calderón's conjecture would follow as a simple corollary. Calderón did not know Kato and Kato did not know Calderón. When they were in the US, Calderón was at the University of Chicago and Kato was at Berkeley. McIntosh explained that the problem I was trying to solve could be rephrased in the terminology of Kato. As soon as I got this information, I discussed with Coifman the possibility of solving the problem through this new formulation. Coifman was excited and wrote a kind of draft version of the solution. Then I returned to France and I managed to find the missing points. So, without my discussion with McIntosh, who knows if the problem would have been solved by me? McIntosh did not play any further role but he knew that the problem had a double meaning, that it could be rephrased inside another completely distinct theory, and with this new perspective on the problem, the problem could be solved. So that is the reason why the paper is signed with the three names. Elias Stein was the Editor-in-Chief of the Annals of Mathematics at the time and he asked me to write the paper in French because it was clear to Stein that I had solved the problem and that just hints were given by McIntosh and Coifman. But I am very proud to have included McIntosh and Coifman as co-authors. Sadly, McIntosh died from cancer recently.

\section{So this actually sprang out of a graduate course?}

Yes, exactly, and just because I dislike following the crowd.

This must be a prime example of solving a problem through rephrasing it in a new mathematical language? Exactly, exactly. When this happens, it always gives me an intense feeling of happiness. This also shows that personality plays an important role in your mathematical life. The fact that I dislike following the crowd. Otherwise, I would never have met McIntosh. By the way, McIntosh worked with my students for about 30 years before he 
died, so it was a great collaboration with the group. I was then doing something else.

Before we drop the Calderón programme and his conjectures, could you tell us briefly what it was all about? In order to explain what Calderón's conjectures are, let me begin with the end of the story. The goal is the computation of the analytic capacity of a compact set $\mathbb{K}$ in the complex plane $\mathbb{C}$. The analytic capacity of $\mathbb{K}$ is 0 if and only if every function $f$ on $\mathbb{C} \mathbb{K}$ that is holomorphic and bounded on $\mathbb{C} \mathbb{K}$ is constant. By Riemann's theorem, the analytic capacity of a single point is 0 . The analytic capacity of an arc of a smooth curve is not 0 . A problem raised by Painlevé is to find a geometric characterisation of compact sets with vanishing analytic capacity. This has been achieved by Xavier Tolsa and the best reference is the Proceedings of ICM 2006. Tolsa's work relies on what was achieved on Calderón's programme. Calderón asked the following. Let $\Gamma$ be a closed rectifiable Jordan curve in the complex plane. Let $\mathbb{U}$ be the bounded domain limited by $\Gamma$ and $\mathbb{V}$ be the exterior domain delimited by $\Gamma$. The Hardy space $\mathbb{R}^{2}(\mathbb{U})$ is the closure of the polynomials in $\mathbb{L}^{2}(\Gamma, d s)$, while the Hardy space $\mathbb{U}^{2}(\mathbb{V})$ is the closure in $\mathbb{L}^{2}(\Gamma, d s)$ of polynomials in the variable $1 / z$ vanishing at infinity. Here, $d s$ is the arc-length on $\Gamma$. Calderón wanted to know whether $\mathbb{L}^{2}(\Gamma, d s)$ is the direct sum of $\mathbb{U}^{2}(\mathbb{U})$ and $\mathbb{H}^{2}(\mathbb{V})$. I proved this fact when $\Gamma$ is a Lipschitz curve. Then, Guy David proved it when $\Gamma$ is a Lavrentiev curve. Finally, David solved the Painlevé problem in a joint effort with Tolsa (David did the first half and Tolsa the second half).

We will now segue from Calderón to wavelet theory, the connecting thread being the so-called Calderón's reproducing identity, which you were intimately familiar with. But before we do that, tell us a little about your encounter with Calderón on a personal level.

I loved discussing with Calderón, also because we could speak in Spanish. I am fluent in Spanish and Calderón was from Argentina. After discussing mathematics, we talked about literature and other expressions of Spanish culture that we appreciated. I liked Calderón very much. He was like a spiritual father for me. He was joking about my political ideas because he was right-wing and I was left-wing, and we talked about Argentina and its political conflicts, which were serious. But even if we disagreed about politics, it was a delight to discuss with him. I have kept in contact with his second wife Alexandra Bellow and from time to time she says that Calderón viewed me as his spiritual son. Yes, I cherish Calderón in a very strong sense.

\section{Wavelets}

We now come to a very exciting part of your research centred on wavelets - ondelettes in French. There is a very fascinating story of how you got into this and how your familiarity with some of Calderón's work turned out to be propitious. Could you tell us about this?

My discovery of wavelets is also completely accidental. It came about through the Head of the Department of
Mathematical Physics at l'École Polytechnique, Jean Lascoux. I was teaching at l'École Polytechnique and I soon became a friend of Lascoux. Jean Lascoux was spending almost all his life at the photocopying machine. Mathematicians and mathematical physicists were sharing the same Xerox machine. He was making several copies of everything, absolutely everything, and distributing copies around. If you needed to make a copy, you had to wait until he had finished. Instead of being irritated, I liked discussing with Jean Lascoux and we soon became friends, and every time Jean had a mathematical problem, he was asking me for an idea or suggestion. And one day - this was in 1984 - he said: "Yves, you should have a look at this paper. I am sure you will be interested." It was a preprint by Jean Morlet and Alex Grossmann about wavelets. What they proved in that paper was a simple version of a theorem by Calderón that I immediately recognised, namely Calderón's reproducing identity. They had the fantastic idea that this could be a revolution in signal processing. So that was a fantastic step. I was immediately excited by the paper and by the way it was written. They were working at the Centre de Physique Théorique in Marseille. So I took the first train to Marseille and I joined the group. I observed that they were using a very clumsy algorithm. They had a continuous version so they wanted a digital version and were just taking Riemann sums and so on and so forth. And then I began discussing with Ingrid Daubechies, who already belonged to the group. The three of them - Morlet, Grossmann and Daubechies - were in a sense ahead of me in their work on wavelets. So I was the "Quatrième Mousquetaire". They were Les Trois Mousquetaires you know d'Artagnan was joining the group - so I was d'Artagnan. I discussed with Ingrid and then I had the idea to try to find an orthonormal basis of wavelets, which would make everything trivial on the algorithmic level. It took me three months of intense work but that is nothing compared to the seven years I spent proving Calderón's conjecture. In just three months, I found the basis.

The wavelet you found was in the space of rapidly decreasing functions, that is, it was in the Schwartz class, right?

That was in the Schwartz class. Then, a year later, I realised that Jan-Olov Strömberg had found another basis some years before. He was, at that time, working in Troms $\varnothing$. Troms $\varnothing$ is a beautiful city in Norway north of the Polar Circle.

The wavelet Strömberg found was a spline function and so it was not in the Schwartz class.

No, it could not be in the Schwartz class. Neither Ingrid Daubechies nor Grossmann nor Morlet were aware of Strömberg's paper because it looked very technical.

We have to interrupt you right there because Strömberg gave a talk about these spline functions of his at a memorial for Zygmund. And you sat and listened to this.

Yes, exactly. I have to confess to that! That was in March 1981 and I was working madly on Calderón's conjecture. 
I was so obsessed with Calderón's conjecture, which I solved in May, that I could not even remember his talk. But it is true - I should be ashamed. My construction is completely distinct from Strömberg's and my solution paved the way for all the other solutions. The solution by Strömberg was more tricky. By the way, Strömberg also had the idea of multiresolution analysis. When I discovered Strömberg's paper, I sent a telegram to Troms $\varnothing-$ emails were hardly used at the time - telling Jan-Olov that he is the father and I am no longer the father of wavelets.

Let us stop for a moment and catch up on what we have been talking loosely about. Could you tell us briefly what is an analysing wavelet and what is a so-called mother wavelet, and how does Calderón enter the picture?

Roughly speaking, the wavelets mimic an orthonormal basis for $L^{2}\left(\mathbb{R}^{n}\right)$ and the reproducing identity is like an expansion of an arbitrary vector in this Hilbert space. In Calderón's formula, one begins with two functions $g(x)$ and $h(x)$ defined on $\mathbb{R}^{n}$ and satisfying the following identity

$$
\int_{0}^{\infty} \hat{g}(t u) \hat{h}(t u) \frac{d t}{t}=1
$$

for all $u$ in $\mathbb{R}^{n}$ distinct from zero, where $\hat{g}$ and $\hat{h}$ are the Fourier transforms of $g$ and $h$, respectively. One denotes by $G_{t}$ and $H_{t}$ the convolution operators associated to $g_{t}$ and $h_{t}$, respectively, where $g_{t}(x)=t^{-n} g\left(t^{-1} x\right)$, and $h_{t}$ is defined similarly. Finally, one obtains the identity

$$
\int_{0}^{\infty} G_{t} H_{t} \frac{d t}{t}=1,
$$

which is Calderón's reproducing identity. In Morlet's approach, $h(x)=\overline{g(x)}$ and $(*)$ is precisely the compatibility condition he imposed on a wavelet. As in the one-dimensional case, the functions $t^{-n / 2} g\left(t^{-1}\left(x-x_{0}\right)\right)$ are called wavelets, the function $g$ being the analysing wavelet. Let's for simplicity assume we are in the one-dimensional case. A mother wavelet is a function $\psi(x)$ such that its set of siblings $\left\{\psi_{k, j}\right\}$, where $k$ and $j$ are integers, and

$$
\psi_{k, j}(x)=2^{j / 2} \psi\left(2^{j} x-k\right)
$$

is an orthonormal basis for $L^{2}(\mathbb{R})$. So the siblings are obtained from $\psi(x)$ by dilations and translations.

But then you took the story further to multiresolution analysis. Perhaps you could say something about that? Yes. Multiresolution analysis is more natural than wavelets. It is my fault that I have always attributed the discovery of multiresolution analysis to my joint work with Stéphane Mallat, while it is due to my joint work with Coifman. So, multiresolution analysis is something completely trivial from the viewpoint of image processing: it is just to zoom in and zoom out - to see an image at distinct scales. Wavelets are the difference between two successive views of the image. So, once we have got multiresolution analysis, all those other constructions were very natural. In analysing an image it is very natural to get another viewpoint, or a better perspective - you zoom in to see some details. It is like the difference between a sequence and a series: multiresolution analysis is a sequence of numbers or a sequence of views of an image; wavelets are the corresponding series, which corresponds to the difference between two terms of the sequence. So it is very natural.

Gauss gave four different proofs of the fundamental theorem of algebra that every polynomial over the complex numbers has a complex root. And he had more than six proofs of the quadratic reciprocity theorem. For the basic theorem within wavelet theory, there exist several proofs. Is it important to have different proofs?

Yes, it is very important because it gives distinct perspectives. It is also important from the viewpoint of the psychology of scientists. For example, there are some people who prefer wavelets visually, having the shape of an oscillating character and so on. Some other people prefer the viewpoint of multiresolution analysis. To the wavelet room, so to say, you can enter through distinct doors and it is good for the public. It was very good to have distinct approaches to wavelets.

\section{Is it true that quadrature mirror filters are closer to ap- plications?}

Yes, and that is the great insight of Stéphane Mallat. Mallat wrote a $\mathrm{PhD}$ thesis in signal processing from the viewpoint of the electrical engineering community. So he belongs somehow to another community. He knew what quadrature mirror filters were. And he was 24 years old when he made this fundamental discovery that wavelets and quadrature mirror filters were telling the same story. That had a fantastic impact because all electrical engineering people were despising wavelets, saying that it is just a foolish theory by crazy mathematicians. Immediately, they changed their opinions, saying that we were all doing wavelets. But my student Albert Cohen discovered that there are some quadrature mirror filters that were used that cannot produce wavelets because when they are iterated you have some kind of instability. People could not explain that within the community of electrical engineering. When you iterated those filters, they did not converge to a wavelet. The good quadrature mirror filters were those that, once iterated, converged to a wavelet. So it illuminated the whole theory. So the discovery of Mallat played a fundamental role.

You have to tell us how wavelets were used for a really spectacular detection. We are thinking of gravitational waves that were discovered a couple of years ago.

Yes, that is also a funny story. It illustrates something I like about science: nothing is exactly the way you dream about it. So, the discovery of gravitational waves does not use my wavelets at all. They use another brand of wavelets that were dreamed about long before I worked on the subject. The first person who dreamed about such wavelets was Dennis Gabor. Dennis Gabor was a Hungarian physicist who won the Nobel Prize for Physics in 1971 for his invention of holography. He was an emigrant 
from Hungary to Great Britain because of Nazism and he wrote a fantastic paper in 1951 about digital speech processing. So this was in 1951, a few years after the transistor was invented. He was already anticipating the digital revolution and the idea that modern telecommunication would transform speech processing into a sequence of $0 \mathrm{~s}$ and $1 \mathrm{~s}$. So, for that purpose, he guessed that there should be a basis in which each signal could be written as a series, a simple series, and it would suffice to transmit the coefficients of the series. That would be enough and that would be the fastest and the most efficient way to transmit speech and sound. But the basis he proposed was completely incorrect and another Nobel Prize winner Kenneth Wilson proposed a slightly different solution than the solution of Gabor. Wilson, incidentally, won the Nobel Prize for Physics in 1982 for his theory about renormalisation. Then, Ingrid Daubechies became aware of the paper by Kenneth Wilson. She was, at the time, working with two of my students, Stéphane Jaffard and Jean-Lin Journé, and they solved the problem. That means transforming the intuition of Kenneth Wilson into a mathematical theorem. So they proposed an algorithm and, by that, both Gabor and Wilson were justified in a sense. It is this algorithm that was used by Sergey Klimenko in his detection of gravitational waves. So, it is a parallel theory of wavelets but they are not the same wavelets as the ones I introduced. It is not zooming into finer and finer scales; it is a problem of catching the right frequency at the right time. It is like hearing a sonata and then writing the score, which is a completely distinct problem. They are both called wavelets but they are solving distinct physical problems.

\section{Other research interests}

You made certain forays into the Navier-Stokes equation. Could you tell us about this?

$\mathrm{Oh}$, yes. That was also marvellous because it was a scientific disaster! Yes, but with a good ending. There was a paper written by Guy Battle and Paul Federbush claiming that using wavelets, time-scale wavelets, zooming into finer and finer scales, you could solve Navier-Stokes. Then, Jacques-Louis Lions, the father of Pierre-Louis Lions, asked me: "Yves, what do you think about this paper; you should read this paper and tell me the true story." So, with my Italian student Marco Cannone, we decided to accept this challenge and to read the paper. And, as usual, when a mathematician reads a paper he just forgets the paper he is reading and tries another tool for solving the problem. We first observed that using the LittlewoodPaley decomposition, which was known already in the 1930s, the proof of the paper could be much simplified. So wavelets did not have to play any role in the paper by Battle and Federbush. And then both of us became interested in Navier-Stokes regardless of wavelets; we just forgot about wavelets. We wanted to see what could be proved, what better theorem could be proved in the programme of Federbush. We obtained some interesting results and we were conjecturing that the best result should be so and so - it is technical. We were unable to prove the best result. The best result was proved by Herbert Koch and Daniel Tataru. So we gave up when we were reaching the final point. The good point is that I had three students working on Navier-Stokes (because as soon as I became interested I was able to convince other people to work in that direction). These three students are excellent (Fabrice Planchon, Lorenzo Brandolese and the already mentioned Marco Cannone) and after completing their PhDs they worked on some other aspects of non-linear PDEs. So, during my Navier-Stokes period, I did not prove anything really interesting. In June, we had a day at l'École Normale Superieure de Cachan for explaining my mathematics to the students. I refused to have someone explaining what I did on Navier-Stokes because I am slightly ashamed. But the beginning was good, you know: I wanted to answer the problem raised by Jacques-Louis Lions. And at the end, there were three excellent $\mathrm{PhDs}$ and the three people are now full professors, and that is fine.

Together with Coifman you did some important work related to pseudo-differential operators, which inspired J.-M. Bony's theory of so-called paradifferential operators and paraproducts. Could you tell us a little about this?

It is true that Bony's paraproducts are an example of the general theory developed by Coifman and I. Nevertheless, in Bony's hands, these operators yielded fantastic estimates on the regularity of solutions of non-linear PDEs (something Coifman and I never thought about).

\section{An intellectual nomad}

You have made contributions in several other fields of mathematics that we have not touched upon. This provokes a meta-question. You have been through various phases. You started in harmonic analysis, you went through number theory for a while and you worked on the Calderón problem and wavelets... Is there a common thread through what you are doing?

No, I have asked myself your question. Of course, the theorem I was describing on Pisot and Salem numbers and Meyer sets has absolutely nothing to do with NavierStokes. No, I like discovering another country. For example, this morning I woke up rather early and decided to explore Oslo by myself. That is just fantastic. I feel I am reborn when I explore a new city without a guide.

In mathematics, there is also this human aspect. You talk to people and you get input from them, and perhaps that changes your direction?

Yes, and most of the time my change is just accidental and under the influence of another person. But the idea to be born again, to start to learn... When I began working on Navier-Stokes, I felt like I was a child because I did all the mistakes you do in the beginning. That is something absolutely fantastic.

Even though you have switched fields several times, your main research thrust has been in what is broadly 
called harmonic analysis. You are the second one to win the Abel Prize in harmonic analysis; the first was Lennart Carleson.

Yes, of course I admire him very much. Lennart Carleson for me is like God, you know. I cannot be compared to Lennart Carleson; he is so much above.

We are not going to compare anybody. But you did use some results by Lennart Carleson at the time?

Yes, of course. I used what are called Carleson measures in a very deep way in the solution of Calderón's conjecture. I worked in a very intense way on his paper on the convergence of trigonometric series. I admire his style very much, not only the deepness of the results but also his style and irony. I am very different from Carleson but he is a model. I wouldn't say that I was close to Carleson the way I was close to Calderón. But it might be because with Calderón I was sharing the Spanish language and the Spanish culture and that helped a lot.

Carleson said in the interview we had with him that he was a problem solver. He was not interested in building theories. Do you count yourself as a problem solver or are you in-between?

I am in-between. For example, in the work on quasicrystals or on wavelets I was more building a theory. For quasicrystals, my book gave something very systematic and when it was rediscovered there were, I would say, hundreds of papers written on Meyer sets. I gave a basis of a theory but once I had done that I got immediately bored and changed subject. I leave it to students. Now, that explains why I have $50 \mathrm{PhD}$ students. One year at the Université Paris-Dauphine, I had 19 students simultaneously.

\section{How did you manage?}

Some of them were finishing but I spent three hours every week discussing with the students, and at that time I lost five kilos! Yes, that was the worst. But I love transmitting the fire to the students and then doing something else. So, it is a way of cheating because it means that it will be their responsibility to make a building from my ideas, while I can escape. Like people who invite their friends and then disappear.

\section{Teaching and outreach}

Actually, you have a very varied teaching experience, from the Prytanée National Militaire all the way to the Grandes Écoles. How has your philosophy about teaching evolved over time?

My teaching evolved very much; my teaching reflects my personality - I am eager to transmit my visions. When you write, you are very cautious. When you are teaching, you can make some slight exaggerations or, you might say, you can be less cautious. And that is very good because, being less cautious, you can take bets on the future of the subject.

You can give your own gut feelings?

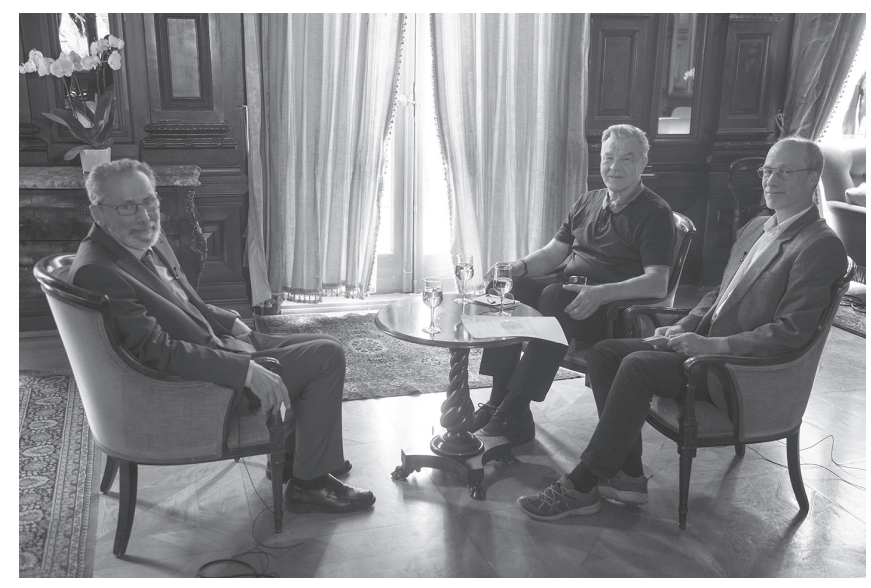

From left to right: Yves Meyer, Christian Skau and Bjørn Ian Dundas. (Photo: Eirik Furu Baardsen)

Yes, and I think the oral aspect of teaching will disappear completely with the new way of courses prepared as electronic versions. It is too controlled.

\section{So, you are sceptical of recording lectures?}

Yes, exactly. I am sceptical because teaching is always an improvisation. It is like a performer: he never plays it exactly the same way twice. When teaching, you can convey the fact that making mistakes could be a benefit for the listener because mistakes can be creative in some way. But that is good for some students and bad for others. Everyone has a way of teaching that is beneficial to a part of the group and negative to the other part. My way of teaching is a way of trying to inspire. I like that people can react and be challenged. The idea is that the group should be challenged: begin to think either one or the other way, even if this is to criticise the view I am trying to convey to them. It is a kind of Socratic experience.

On a higher level, you have been quite clear on your views on the French model for higher education. In view of recent developments in France, do you have a new take on that?

Yes, this is a very important problem because there are several theories about how to improve the teaching of mathematics in France. I was very moved by the presentation of Hanan Mohamed Abdelrahman [the winner of the Holmboe prize 2017] this morning. She made a very important point: give the same challenges to all students. In France, we have the tendency to say that we should not be as demanding with this group as with that group. But this is a way of underestimating the group to which you are less demanding. "This poor person coming from the North of Africa is so unhappy that we should not demand too much." But that is terrible for them!

\section{Are you thinking of distinctions between the universities and the Grand Écoles?}

That is another point, yes. I was speaking of high school level. It is a very difficult problem - it is a problem that cannot be solved in a theoretical way. For example, in the beginning, there existed an École Normale Supérieure de jeunes filles (for young girls) and an École Normale 
Supérieure de garçons (for boys). So, every year, in mathematics, there were 14 girls admitted to the exam for girls. And then a lot of very bright women in mathematics - faculty members - were women coming from l'École Normale Supérieure. They decided that this was unfair, that it underestimated women and that we should unify. Now it is unified and every year the total number is 44 in mathematics: there are 40 boys and 4 women (at most). And sometimes there are no women at all. It is a complete disaster!

It is difficult to find one solution for a big problem. The fact is that all the young students are distinct; they have distinct needs, they have distinct demands and they have distinct abilities. Should we say that their level is equal by definition and that we should impose the same burden on all or should we have an honours class? This is very difficult.

We wanted to talk about outreach. What do you think about the importance of popularising mathematics, like your own work? Is that futile?

On that I do not know. I can just give you an interesting example. In Tunis, cultural life was rather narrow because it was so far away from Paris at that time. Planes hardly existed and we took the boat to go to France. So, when a person was coming far away from France, it was a local attraction. As a high school student, I went to a talk given by Jean-Pierre Kahane. I remember the subject he was talking about was very interesting; it was a problem of trigonometric series he was trying to solve. He gave a talk - and he is a very good speaker - in such a way that I understood what he was talking about. I was a student in high school. I was truly fascinated. I was fascinated by his personality. Later, I went to Orsay and was there for about 15 years, and he had had a great influence on my work. What he did when he came to Tunis was a kind of popularisation of mathematics: going to Tunis, giving a talk for a general audience about his research.

It was quite exceptional and I would like to say that this influenced my work. I cannot prove that it truly influenced my work. It might have been just something accidental but I love the story.

On the topic of popularising mathematics, Ludvig Sylow was a Norwegian mathematician and, in his eulogy at Sophus Lie's funeral, he said the following: "It is the mathematician's misfortune more than the other scientists, that his work cannot be presented or interpreted for the educated general public, in fact, hardly for a collection of scientists from other fields. One has to be a mathematician to appreciate the beauty of a proof of a major theorem or to admire the edifice erected by mathematicians over thousands of years." That was Sylow's attitude.

I slightly disagree. Because the point is that there is nothing special about mathematics. Take difficult literature or poetry, for example. I would say that I do not understand the living French poets. I try to read their poems and I do not understand them. The problem with mathematics is that people do not even understand the language. In the case of poetry, to be completely honest, I understand the words but I do not understand the language. It means that, for every aspect of art, the difficulties are the same. Like modern music - have you heard a work by Xenakis?

\section{Yes, I have.}

But you did not understand it!

No...

No, but people never say that, you know. They think they understand music but they do not understand music either! And nobody talks about that.

\section{Private passions}

Perhaps concluding the interview, are there aspects that are not regularly touched upon? Some passions - private passions?

I have private passions. Yes, I have several passions. I am a passionate person.

People, I would say. I like people. I like discussing with people - meeting, admiring people. I would say the pleasure to do mathematics is related to the pleasure of joint work. Let me single out Raphy Coifman. I have been working with him for 40 years. He is like a brother and he is viewing me as a brother. I like his personality. I like his life.

I like people, and everything that is related to literature. My first addiction was literature - I took humanities as a child. I am still enjoying Plato with delight.

\section{In Greek?}

I am no longer reading Plato in Greek. I used to. And I was still doing that at l'École Normale Supérieure. In that way, I was admired by students in humanities and despised by scientists because a true scientist does not read Plato. I also love reading the Bible.

\section{Both the Old and the New Testament?}

Only the Old Testament. It is more spicy, you know: David and Bathsheba, and the relationship of David and Jonathan. It is completely fascinating because there is a smell of homosexuality. And the mourning of David when Jonathan dies - it is beautiful.

\section{That is great poetry also.}

Yes, it is completely marvellous that David said that their friendship was more important than the love of a woman. It is completely fascinating.

\author{
Also the story with Abraham sacrificing Isaac. You \\ know that ... \\ Kierkegaard...
}

Kierkegaard, exactly! Søren Kierkegaard was extremely fascinated by the story about Abraham and Isaac. His book "Fear and Trembling" ("Frygt og Baven") is centred on this story.

Beyond mathematics, my very deep world is literature. 


\section{Also Russian literature, we understand?}

Yes! Vasily Grossman, for example, and Aleksandr Solzhenitsyn and Anton Chekhov. I know by memory Tolstoy's Anna Karenina.

\section{We heard the story that you even found wavelets in Rus- sian literature.}

Yes, in Solzhenitsyn's The First Circle. There you find not wavelets exactly but time frequency analysis. Solzhenitsyn was a physicist and then moved to literature - because of the war, because he was sent to a concentration camp. And he could not resist writing in The First Circle a chapter on time frequency analysis. I will not describe it - it is too long - but there is a page that I read each time I give a course on signal processing because it is so beautiful. $\mathrm{He}$ is describing exactly the problem that I will be describing on Wednesday: to catch something inside a signal, to catch a pattern. The problem in the detection of gravitational waves was to catch a specific pattern that would be the signature of the gravitational wave. The signal is completely noisy and the noise is a thousand times larger than the signal. So, we have to capture these very small, short-lived patterns. In The First Circle, it is an audio signal, a recording of the voice of someone, and the group has to detect the person through finding the characteristic patterns of the person, patterns that would be for the person the equivalent of fingerprints - the patterns of a voice. Solzhenitsyn calls that "voice-prints". He is describing the problem truly as a physicist, using the correct words and so on. It is completely fascinating. So, my interest in Russian and Soviet literature is related to my research work, as everything is... Of course, for students - but I am not teaching anymore - the problem when you speak about Solzhenitsyn today is that they don't know Solzhenitsyn, and the two of them who do know Solzhenitsyn have nev- er read The First Circle. And then, when I am reading a page of The First Circle, they just fall asleep.

\section{Do you have other interests beside mathematics and lit- erature?}

I like music - I am very fond of music. And I love painting.

\section{Some special painters?}

Oh, yes. But that changes from age to age. I would put at the very top two Spanish painters: Goya and Velázquez. I have special ties with Spain. But that is very personal. I wouldn't say that they are the greatest painters in the world but I love Goya.

\section{On behalf of the Norwegian Mathematical Society and the European Mathematical Society, thank you very much for this interview. It has been most interesting.}

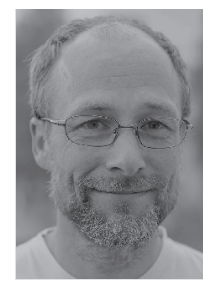

Bjørn Ian Dundas is a professor of mathematics at the University of Bergen. His research interests are within algebraic $K$ theory and algebraic topology.

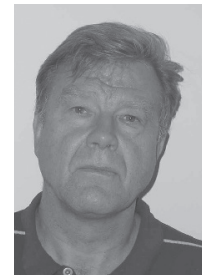

Christian Skau is a professor emeritus of mathematics at the Norwegian University of Science and Technology (NTNU) at Trondheim. His research interests are within $C^{*}$ algebras and their interplay with symbolic dynamical systems. He is also keenly interested in Abel's mathematical works, having published several papers on this subject.

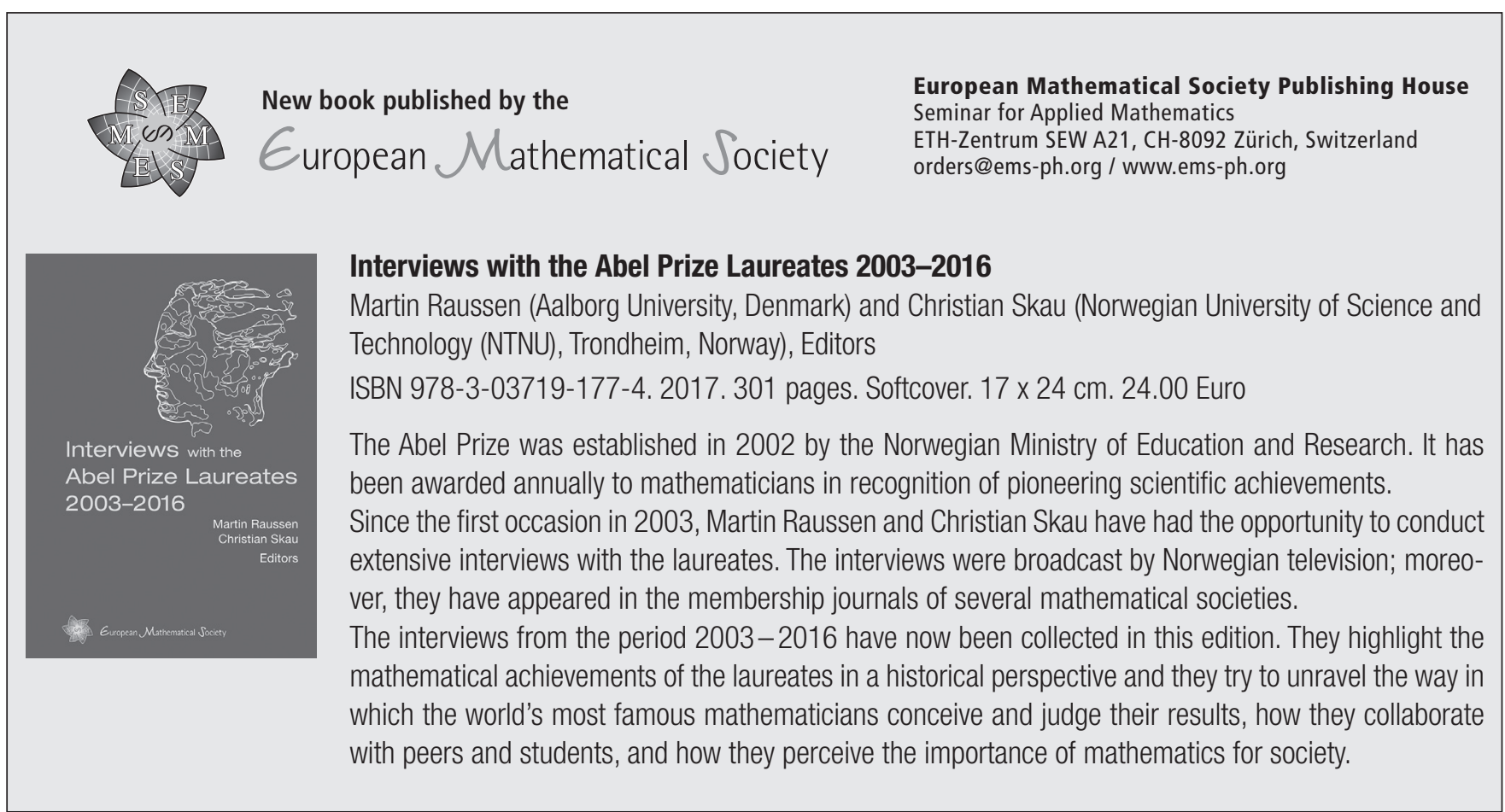

